\title{
Assessing the impact of Authentic Leadership and Team Climate on Innovative Work Behavior within Self-managed teams in IT Organizations
}

\author{
Dr. Rajeesh Viswanatha, Divya Lakshmi
}

\section{Abstract: \\ Purpose:} Authentic Leaders in the follower's perspective, The study constructs of Team Climate on Innovative Work Behaviour within Self manged teams in IT organisations.

Design/Methodology/Approach:

The sample data has been obtained from five major IT organizations in Chennai and Bangalore region. Selected organizations mainly comprise of the Software Developer's Team under the Self-Managed Team base.

Findings:

Authentic leadership develops the feeling of trust among the team members and facilitates a conducive climate. Only in such scenarios it would lead to affirmative discussion and optimistic criticism which would enable to overcome lacunas if any. Conducive climate develops the trust and confidence among the team members where by employees gain the confidence of trying innovative ideologies.

Implications:

To create such an environment organization should create an ideal structure with maximum work autonomy along with accountability and responsibility. In other words, hygiene factors coined by Herzberg should be existing only then we can motivate the employees.

Scope:

The study involves only one particular form a leadership style whereas the study can be examined under various forms of leadership styles, Ekvall and Arvonen in the year 1994 identified a blend of leadership style which exhibited the leadership style possessing traces of three different leadership styles.

Index Terms: Authentic Leadership, Team Climate,Innovative Work Behaviour, Self manged teams, Trust.

The Effect of Authentic Leadership and Team Climate on Innovative Work Behaviour within Self-managed teams in IT Companies.

\section{INTRODUCTION}

Authentic Leadership was observed as the positive form of leadership style in the recent scenario. According to Walumbwa, Avolio, Wernsing, Peterson and Gardner in the year 2008 it is a trim of the leadership style that brings about the two prominent changes in the leadership behaviour. The

Revised Manuscript Received on July 05, 2019.

Dr. Rajeesh Viswanathan, Dept of International Business, School of Management, Pondicherry University, Pondicherry.

Divya Lakshmi, Dept of International Business, School of Management,
The main aim of this study is to assess the role played by Pondicherry University, Pondicherry.

changes are brought about in the phase of positive capacity of the psychology trends and an ethical climate in order to produce a greater impact of positivity on its four important phases such namely self-awareness, balanced processing of information, an internalized moral perspective and relational transparency on par with the employees striving for a positive self-development along with the leaders. The judicial aim is to study the impact of Authentic Leadership on Innovative Work Behaviour and the study also tests the impact of a conducive team climate on the Innovative Work Behaviour (IWB).

Authentic Leadership has four distinct behaviours as stated above and it aids to form a strong theoretical background for the concept. A model for Team Climate was proposed by West (1990), Team Climate for Innovation is yet another dimension focussed in order to find its effect on the Innovative Work Behaviour and it has been split up into four major factors namely Participative Safety which validates about the work atmosphere and thereby checks the compatibility for the participation of the work teams.

Support for Innovation can be sensed with 3 major perspectives namely like support through verbal means, support through extending co-operation to the peer group through helping them in generation of new thoughts or ideas for development or extension of support through aiding with resource allocations or by even means of time allocation. According to Gustafson and Agrell, 1994; Anderson and West, 1996 Team climate can be identified by evaluation of certain processes such as participation in high levels, an insistence of a qualitative support for innovation can be observed as an innovative support extension for teamwork concepts.

Innovation is a term that changes with a systematic level of study being involved. Damanpour in the year 1987 has categorized this innovation into two major sectors namely Technical and Administrative. The technical innovations are those which are involved directly with the technical systems of an organization and in turn related to the primary tasks of the organisation. Administrative innovations are those that are related with the levels of innovations those involved with the structure of the organisation and with the management of the employees and related issues. The innovative behaviour at workplace involves Scott and Bruce(1994 ) inventory which has 3 major dimensions like Generation, Promotion and Realization of Idea. The

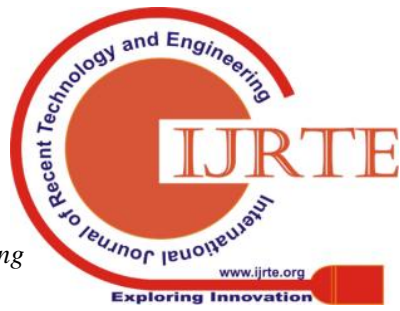


ideology is to find out how often the employees execute these innovative work behaviours at workplace.

\section{REVIEW OF LITERATURE}

Team Climate on Innovative Work Behaviour (IWB)

Caroline Burningham and Michael A. West in their Small Group research on Individual Climate and Group interaction processes as predictors of Work Team Innovation have done an extensive study on the role played by an innovative capacity of an individual and Factors pertaining to Team Climate on Innovative capacity while in work team. The study was conducted in an Oil company comprising of 59 members in a group of 13 teams. Caroline Burningham and Michael A. West to evaluate the range of work team innovation relies on the four factors of the Team Climate Index Namely Participative Safety, Task Orientation, Team Vision and Support for Innovation. The findings from the research study shows that the ratings obtained from the predictors of Team Climate and Innovation process pertaining to group were externally related to the measures of Group Innovativeness. Research observations also say that the innovation support module from the Team Climate Index (TCI) has been noted to be the most consistent module and all the four dimensions of TCI are all significantly correlated with the innovativeness quotient and hence also delivers an eminent support to the theoretical predictors as well.

Neil Anderson \& Michael A. West in their study Development of Team Climate Instrument (TCI) and its application on innovation for building up of a teamdescribes about the application and development of TCI and also the functions involved in a group in order to validate its contribution involved in Team building and thereby its impact on Team innovation. The researchers have done two case studies for diagnosing the developed TCI. The researchers have included the work and organization (W/O) psychologists and personnel practitioners in the study. They are made to be more focused upon their competence in existence and also the measurement skills concerned with individual assessments. The cases involved in the study deals with the phenomena in organizations based upon the three suppositions namely the international changes in the business environment, the new practices in organizations have promoted more of Team working within the employees and the $\mathrm{W} / \mathrm{O}$ practitioners are not on par with these trends and hence fail to meet the demands of the HR practitioners. The researchers have concluded by saying that the W/O psychologists have shown active participation in the team and also had involved themselves into enhancement of team innovativeness.

\section{The role Leadership and Climate for Innovation in Teams}

Ingrid Dackert, Lars-A ${ }^{\circ}$ keLo“o”v and MalinMartensson Kristianstad University, Sweden has done a research work on Leadership and Climate for Innovation in Teams. The intent of this study was to understand the impact of leadership behavior and the role of a conducive team climate on Team Innovativeness. The findings imply that there has been a positive correlation with the leadership model persistent in organizations. This Leadership model is a combination of the both the change orientation and the employee's orientation as well. The innovation as a complete module is also been influenced by the persistent climate prevailing in that particular organization. In this approach it has been observed that the innovation process deals with the active participation and the objectives have also been considered with due clarification. They are associated with the membership of the team rather than the style of leadership into existence.

Matej $\mathrm{C}^{`}$ erne, MarkoJaklic ${ }^{\smile}$ MihaS`kerlavaj in their research study that deals with the innovative and creative behavior under an Authentic Leader on a perspective of multiple dimension have developed a multilevel model to empirically test and study the cross-level interactions that exists between Authentic Leadership and Innovation in teams. The research study intends to take into consideration the support for innovation and the creativity which is to be observed at the individual level. The study has been done on 23 team leaders and tis into production of innovative products and also deals with customer solutions. They had employed in a technique called Hierarchical Linear Modelling (HLM) in order to perform the analysis under multilevel dimension. The outcome of the analysis shows that the Authentic Leadership shows a positive indication towards the team members, creativity at the individual level and the innovation in teams. The main highlight of the study is that it uses a multilevel approach through (HLM) which is the very first attempt made by the researchers in order to study and quantitatively validate the affiliation within the three study constructs namely the Authentic leadership, Team innovation and Creativity at the individual level. The other remarkable thing in the study would be that the researchers have carried out the analysis based on empirical data despite the other ground studies that solely relied upon the source of information.

\section{Research Gap and Research Problem:}

The study focuses on authentic leadership style. Hardly any research studies have been done on it. There were no research studies relating to this leadership style which has a good impact from the employee's perspective too. In order to attain a sustained performance, the leaders should posses certain qualities that motivates, develops and restores confidence amongst employees and creates organisational citizenship quality thereby retains them in the company. Involving Team Climate as one more independent variable would further enlighten the study as these two variables definitely would possess a stand in innovative work behaviour (IWB) of an employee.

\section{Methodology}

The desire of this study is to assess the impact of Authentic Leadership and Team Climate on Innovative Work Behavior in Teams. The sample set for the study was collected from the software developers from various IT organizations. The Authentic Leadership involved in this study would be observed as the most positive forms of leadership that serves as the origin and grounds for any positive form of leadership style. The team climate instrument (TCI) for the study also has been tested for its impact on the Innovative Work Behavior in teams.

\section{Samples and Procedures}

The intent of this research is to assess the impact of Authentic Leadership and Team Climate on Innovative Work Behavior in Teams. The sample set for the study has

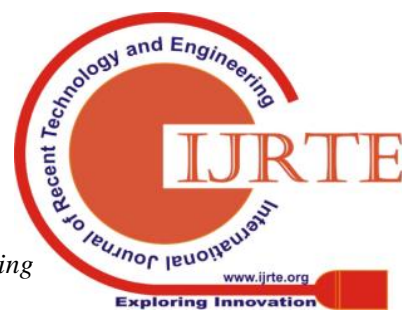


been collected from the software developers from various IT organizations from the top five IT companies as per NASCOM(2016) report in Bangalore and Chennai region. The sampling technique is a probability sampling which can be confined to the Multistage Stratified sampling design. The Authentic Leadership involved in this study would be conceived as leadership styles which possess a positive attitude that serves as the origin and grounds for any positive form of leadership style. The team climate inventory (TCI) used in the study also has to tested for its impact on the Innovative Work Behavior in teams.

The data used for the study is empirical though some of the base studies were found to contain information form appropriate sources. The basic tools used for analysing the data were IBM SPSS Statistics20 and multiple regressions were performed using AMOS Graphics for running the Structured Equation Modelling Technique (SEM).

\section{Scale Development}

The variables under the study are Authentic Leadership (Independent), Team Climate (Independent) and Innovative Work Behaviour (Dependent). The Authentic Leadership Scale was developed by Avolio \& Walumbwa (2006) has four dimensions consisting of 14 items in the scale, the four include dimensions namely Internalized Moral Perspective (IMP) (4),Self Awareness (4), Balanced Processing(2).The other independent variable in this study is Team Climate Inventory(TCI) which also uses the five point Agreement scale as that of Authentic leadership also contains four dimensions namely Task Orientation(7),Participative Safety(7), vision(12) and Support for Innovation(8) which accounts to nearly 34 items. The scale was developed by Neil.R.Anderson and Michael A.West (1994).The Dependent variable in this study is the Innovative Work Behaviour (IWB) and was developed by Scott and Bruce's (1994) and this IWB scale have designed to understand the individual's Innovative Work Behaviour at Workplace it consists of nine items and has three different dimensions build within it namely the Generation, Promotion and Realisation of Idea under study constructs.

The conceit was to indicate how often the employees gets hand on Innovative Work Behaviour at workplace and the responses considering the scale that was received in the form of Never to Always five point scale.

\section{OBJECTIVE}

The mission of the research study pertains to assess the relation of Authentic leadership and the team climate on Innovative Work Behaviour within Self-managed teams. To study the contribution of attributes of Authentic Leadership towards IWB and to learn about the climate persistent and their role in promoting IWB amongst employees in IT companies.

\section{HYPOTHESIS DEVELOPMENT}

The model in detail evaluates the impact of Authentic Leadership (AL) and Team Climate (TC) on Innovative Work Behavior (IWB).Hypothesis has been formed under the basis of the theoretical framework of the study variables.

$\mathrm{H} 1_{\mathrm{a}}$ : There exists no relationship between Authentic Leadership and Innovative Work Behaviour.
$\mathrm{H}_{\mathrm{b}}$ : There exists significant positive relationship between Authentic Leadership and Innovative Work Behaviour.

$\mathrm{H} 2$ a : There exists no significant positive relationship between Team Climate and Innovative Work Behaviour.

$\mathrm{H} 2_{\mathrm{b}}$ : There exists significant positive relationship between Team Climate and Innovative Work Behaviour.

The study hence aims at testing the above mentioned hypothesis and arriving at a feasible conclusion for the research study.

\section{SEM-MODEL}

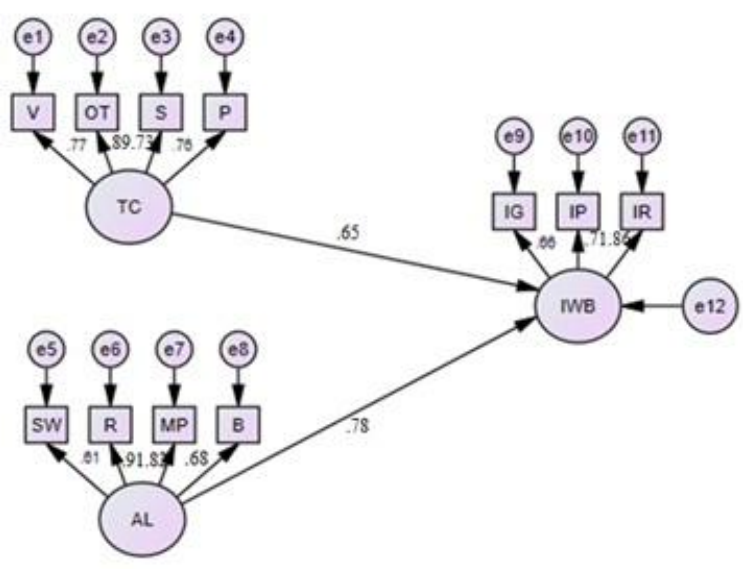

Standardized Regression Weights: (Group number 1 Default model)

\begin{tabular}{|lll|r|}
\hline & & & Estimate \\
\hline IWB & $<---$ & TC & .652 \\
IWB & $<---$ & AL & .783 \\
V & $<---$ & TC & .769 \\
OT & $<---$ & TC & .892 \\
S & $<---$ & TC & .731 \\
P & $<---$ & TC & .762 \\
SW & $<---$ & AL & .614 \\
R & $<---$ & AL & .910 \\
MP & $<---$ & AL & .832 \\
B & $<---$ & AL & .686 \\
IG & $<---$ & IW & .654 \\
& & B & .714 \\
IP & $<---$ & IW & B \\
IR & & IW & .865 \\
\hline
\end{tabular}

\section{CMIN}




\begin{tabular}{|l|rrrrr|}
\hline Model & NPAR & CMIN & DF & P & $\begin{array}{r}\text { CMIN/D } \\
\text { F }\end{array}$ \\
\hline Default model & 15 & 211.3 & 65 & .00 & 3.245 \\
Saturated model & 28 & .000 & 0 & & \\
$\begin{array}{l}\text { Independence } \\
\text { model }\end{array}$ & 7 & 443.3 & 21 & .00 & 21.113 \\
\hline
\end{tabular}

\section{Model Fit}

Model Fit is tested to assure whether the evolved model fits in with the variables form the given dataset. The model fit also portrays whether the data is under a good fit, Model fit decision is made with the considering the significance value and its correlation with the proposed model. In order to verify the model specific measures are taken into consideration. Measures that are considered for model has been listed below.It is to be noted that the Goodness of contrarily proportional to the example estimate as proposed by Hair et al (2010).The limits recorded with reference to $\mathrm{Hu}$ ,Bentler(1999).

\section{Baseline Comparisons}

\begin{tabular}{|l|rrrrr|}
\hline Model & $\begin{array}{r}\text { NFI } \\
\text { Delta1 }\end{array}$ & $\begin{array}{r}\text { RFI } \\
\text { rho1 }\end{array}$ & $\begin{array}{r}\text { IFI } \\
\text { Delta2 }\end{array}$ & $\begin{array}{r}\text { TLI } \\
\text { rho2 }\end{array}$ & CFI \\
\hline Default model & .795 & .870 & .801 & .876 & .800 \\
Saturated model & 1.000 & & 1.000 & & 1.00 \\
Independence model & .000 & .000 & .000 & .000 & .000 \\
\hline
\end{tabular}

\section{Parsimony-Adjusted Measures}

\begin{tabular}{|l|rrr|}
\hline Model & PRATIO & PNFI & PCFI \\
\hline Default model & .864 & .895 & .858 \\
Saturated model & .000 & .000 & .000 \\
Independence model & 1.000 & .000 & .000 \\
\hline
\end{tabular}

\section{RMSEA}

\begin{tabular}{|l|rrrr|}
\hline Model & RMSEA & LO 90 & HI 90 & PCLOSE \\
\hline Default model & .046 & .034 & .031 & .000 \\
Independence model & .332 & .324 & .340 & .000 \\
\hline
\end{tabular}

\begin{tabular}{|l|l|l|l|l|}
\hline Model & RMR & GFI & AGFI & PGFI \\
\hline Default model & .044 & .847 & .976 & .881 \\
\hline Saturated model & 1.000 & 1.000 & & \\
\hline Independence model & .286 & .291 & .182 & .252 \\
\hline Zero model & .000 & .000 & .000 & .000 \\
\hline
\end{tabular}

\section{I) Modification indices}

Modification indices give the difference between the model that has been proposed and the estimated threshold values. Thus, helps us to avoid discrepancies by varying the error terms and thereby considering the CFA values and provides a good model fit.

\section{Findings and Implications:}

Authentic leadership enhances the feeling of trust among the team members and facilitates conducive climate. Only in such scenarios it would lead to affirmative discussion and optimistic criticism which would enable to overcome lacunas if any. Conducive climate develops the trust and confidence among the team members where by employees gain the confidence of trying innovative ideologies. The variables for this study are Authentic leadership, Team climate and Innovative work behaviour. When Authentic leadership\& team climate is persistent under a conducive working climate in a team it would act as a catalyst which induces an innovative work behaviour. Authentic leadership style always puts forth the pros of a particular team functioning rather than its cons, hence it is observed to be the most positive form of leadership which in turn boosts the creative and innovative skills of a team. In other words Authentic Leadership is becoming popular as its name suggests it is opined as one of the Genuine form of a leadership style as it induces emotional safety amongst the peer group and hence enhances creative and innovative minds in teams.

Team climate Inventory has four major dimensions namely Task orientation, support for innovation, Participative safety and vision. Vision is one of the foremost component that has to be taken into consideration for a climate that contributes at its best for Innovative Work Behaviour.

An organization to enhance productivity there is a need to create conducive working environment. This is possible only if they apply authentic leadership. Authentic leadership develops the feeling of trust among the team members and facilitates a conducive climate. Only in such scenarios it would lead to affirmative discussion and optimistic criticism which would enable to overcome lacunas if any. Conducive climate develops the trust and confidence among the team members where by employees gain the confidence of trying innovative ideologies. They feel comfortable in sharing their thought process and will be open in accepting and learning newer methods.

To create such an environment organization should create an ideal structure with optimum work autonomy along with accountability and responsibility. In other words, hygiene factors coined by Herzberg should exist only then we can motivate the employees. The study involves only one particular form a leadership style whereas the study can be examined under various forms of leadership styles, Ekvall and Arvonen in the year 1994 identified a blend of leadership style which exhibited the leadership style possessing traces of three different leadership styles.

Authentic Leadership (AL) and Team Climate (TC) its impacts on Innovative Work Behavior (IWB).

Effectiveness of a team comes when there exists a conducive working environment. This is facilitated by the presence of the team leader. Team leaders leadership style place a vital role in enhancing the effectiveness of the team provided the leader is authentic in nature. With this leadership style he is able to feel the pulse of the team members and the working environment and then motivate them accordingly. Once the team leader is able to perceive what is in the mind of the employee in the current scenario, team leader can modulate the behavior according to attain the needs of the organization and same time keeping the morale of the employee high. Creating such an environment helps in enhancing the mutual trust among the team members and paves way for putting across new ideas and thoughts which would in turn help in coming out with innovative ideas. Hence, its felt that authentic leadership style and team climate facilitates in providing innovative work behavior. 


\section{Authentic Leadership and Innovative Work} Behaviour.

Authentic leadership helps enhances the level of reliability among the team members. Trust built among and between the team members is very high. With this operating style team leader is able to mould and groom the employees according to the vision of the organization where by team leader is able to mutate the behaviour to be more open. Once team members build up openness then tend to share their ideologies facilitating new thoughts. This leads $t$ enhancement of employee's level innovativeness, where by paving way for innovative work behaviour. Hence, it is understood that Authentic Leadership assumes an essential job in making a conducive working environment facilitating innovative work behaviour.

\section{SCOPE FOR THE FUTURE STUDY}

The study involves only one particular form a leadership style whereas the study can be examined under various forms of leadership styles, Ekvall and Arvonen in the year 1994 identified a blend of leadership style which exhibited the leadership style possessing traces of three different leadership styles and then brought about a combination with 3 major dimensions portraying that newly obtain leadership pattern hence there is also a scope for the study to exposed to such a new combination of leadership style developed by the researchers and the observe their innovative behavior at work place.

\section{REFERENCES}

1. Anderson, N. R., \& West, M. A., Measuring climate for work group innovation: development and validation of the team climate inventory. Journal of organizational behavior, 1998, pp. 235-258.

2. Bain, P. G., Mann, L., \&Pirola-Merlo, A., The innovation imperative: The relationships between team climate, innovation, and performance in research and development teams. Small group research,32(1), 2001, 55-73.

3. Burningham, C., \& West, M. A., Individual, climate, and group interaction processes as predictors of work team innovation. Small group research, 26(1), 1995, 106-117.

4. Černe, M., Jaklič, M., \&Škerlavaj, M. (2013). Authentic leadership, creativity, and innovation: A multilevel perspective. Leadership, 9(1), 63-85.

5. Dackert, I., Lööv, L. Å., \&Mårtensson, M. (2004). Leadership and climate for innovation in teams. Economic and Industrial Democracy, 25(2), 301-318.

6. Imran, R., Saeed, T., Anis-Ul-Haq, M., \& Fatima, A. (2010). Organizational climate as a predictor of innovative work behavior. African Journal of Business Management, 4(15), 3337.

7. Leroy, H., Palanski, M. E., \& Simons, T. (2012). Authentic leadership and behavioral integrity as drivers of follower commitment and performance. Journal of Business Ethics, 107(3), 255-264.

8. Liu, F. C., Cheng, K. L., Chao, M., \& Tseng, H. M. (2012). Team innovation climate and knowledge sharing among healthcare managers: mediating effects of altruistic intentions. Chang Gung Med $J, 35(5)$, 408-419.

9. Mathisen, G. E., Einarsen, S., Jørstad, K., \&Brønnick, K. S. (2004). Climate for work group creativity and innovation: Norwegian validation of the team climate inventory (TCI). Scandinavian Journal of Psychology, 45(5), 383-392.

10. Pilař, L., Pokorná, J., \&Balcarová, T. (2014). Pro-active Behaviour in Context of Team Climate. Acta UniversitatisAgriculturae et SilviculturaeMendelianaeBrunensis, 62, 72.

11. Walumbwa, Fred O., Fred Luthans, James B. Avey, and Adegoke Oke. "Retracted: Authentically leading groups: The mediating role of collective psychological capital and trust." Journal of organizational behavior 32, no. 1 (2011): 4-24.

12. West, M. A., \&Altink, W. M. (1996). Innovation at work: Individual, group, organizational, and socio-historical perspectives. European Journal of Work and Organizational Psychology, 5(1), 3-11.
13. Yidong, T., \&Xinxin, L. (2013). How ethical leadership influence employees' innovative work behavior: A perspective of intrinsic motivation. Journal of Business Ethics, 116(2), 441-455. 